\section{Rationality, Political Orientation, and the Individualizing and Binding Moral Foundations}

\author{
Kilian Garvey*, Timothy G. Ford \\ University of Louisiana at Monroe, 329 Strauss Hall, 700 University \\ Avenue, Monroe, LA 71209, USA \\ "Author for correspondence (garvey@ulm.edu
}

Is moral cognition rational or intuitive? This paper tests two competing theories of moral cognition: rational (i.e., Piaget and Kohlberg) vs. intuitive (i.e., Shweder and Haidt) through an investigation of the relationships of each to Haidt's pluralistic moral theory. Haidt's theory claims that, in addition to an individualizing foundation (i.e., justice and harm avoidance), morality also includes a binding foundation (i.e., group and authority deference). Participants $(n=371)$ completed a survey comprised of measures of rational and intuitive cognition, political orientation, disgust sensitivity, and the individualizing and binding moral foundations. The present study found that rational thinking was the strongest predictor for both of the individualizing (harm/care and fairness/reciprocity) and two of the three binding moral foundations (ingroup/ loyalty and authority/respect). Political orientation and disgust sensitivity, found in past studies to be related to these two moral foundation subscales, were related but more weakly, relative to rationality. Haidt claims that moral cognition is intuitive. However, we found a more complex picture: low rational and high intuitive scores are characteristic of the binding moral foundations, but the opposite is true of the individualizing moral foundations.

\section{Keywords}

morality, rational, experiential, political orientation, disgust

\section{Introduction \\ The work of Piaget (1965) and Kohlberg (1969) points to morality and moral development being largely rational, acquired through deliberate role-taking situations, and marked by a particularly salient sense of universal justice and harm avoidance. In contrast, the social intuitionist model of moral development suggests that morality is largely emotional and/or experiential/intuitive and is likely to value the traditions and authority of the group as much or more than the rights of the individual (Shweder \& Haidt,}

2000).

Cognition has been defined as a dual process: intuitive, or System 1, and rational, or System 2 (Stanovich \& West, 2000). System 1 is fast, emotional, and evolutionarily older than System 2, which is slow, deliberate, rational, and has a relatively brief evolutionary history. The social intuitionist model claims that moral decision making is largely, if not entirely, intuitive (System 1) but provides only anecdotal evidence of subjects' inability to give rational explanations of why incest, pornography, or flag desecration is "wrong." While these examples of moral decisions are clearly non-rational and driven by feelings of disgust and ingroup loyalty, we believe they represent only one subset of moral decision making. Haidt and Graham's (2007) Moral Foundations Questionnaire (MFQ) contains both items referring to disgust and ingroup considerations (i.e., the binding foundations), which are intuitively processed (System 1), and items referring to universal harm, rights, and justice (i.e., the individualizing foundations), which, we argue, require rational (System 2) processing. However, to date the social intuitionist research has not included a measure of rationality, and, thus, its relationship to the dual foundations of morality (individualizing and binding) has not been fully explored. Following Lahti (2009) and Dunbar (2003), who hypothesize that intelligence and morality co-evolved in concentric circles of increasing inclusion-from intuitive ingroup nepotism to rational outgroup collaboration - we believe that a measure of individual differences in intuitive and rational cognition will reveal individual differences in moral foundations.

Haidt and Graham (2007) also point to political orientation to explain differences in moral judgments. They demonstrate that political conservatives tend to value the binding moral foundations more than liberals, but liberals tend to value the individualizing moral foundations more than conservatives. While this may be true, because ingroup partiality (Hamilton, 1964) and disgust sensitivity (Tybur, Lieberman, \& Griskevicius, 2009) evolved long before the first hominids, and moral consideration towards non-kin has evolved relatively recently (Lahti \& Weinstein, 2005), it is our contention that modern human political orientation is not likely to explain differences in moral judgments as well as System 1 and System 2 cognitive faculties.

The purpose of this paper is to investigate more fully the relationships of these constructs (i.e., rational/experiential cognition, political orientation, and disgust sensitivity) to the individualizing and binding foundations of moral decision making. In doing so, we advance three hypotheses to be tested: First, that evolutionarily older System 1 cognition will be positively related to the evolutionarily older binding morality (Lahti, 2009), and that evolutionarily more recent System 2 cognition, as measured by the Rational-Experiential Inventory (REI; Pacini \& Epstein, 1999), will be positively related to the evolutionarily more recent individualizing morality. Second, that the evolution- 
arily older emotion of disgust will be positively related to binding morality and negatively related to individualizing morality. Third, that rationality will predict both individualizing and binding morality better than political orientation.

To test these hypotheses, we replicated Haidt and Graham (2007) by examining the relationship of the individualizing and binding subscales of the MFQ to political orientation. We extended this work by including an objective measure of rational versus experiential thinking, which the social intuitionist model of morality alludes to but never directly measures. Additionally, we included a measure of disgust sensitivity, the most commonly utilized measure of emotion in the social intuitionist model.

\section{Method}

\section{Participants}

In total, 371 undergraduates (123 males, mean age 22.29, ranged 18 to $58, S D=6.97$ ) from two colleges in Maine (USA) participated for extra credit. They responded to a paper and pencil questionnaire during class without the class instructor present.

\section{Instruments/Measures}

(i) The Moral Foundations Questionnaire

The MFQ (Haidt \& Graham, 2007) is a 40-item assessment of moral attitudes. It asks subjects to consider the relevance of five moral concerns (harm/care, fairness/ reciprocity/justice, ingroup/loyalty, authority/respect, and purity/sanctity) when deciding whether something is right or wrong. Subjects responded on a six point scale ranging from "not at all relevant" to "extremely relevant." Following prior psychometric research, items from these five subscales were collapsed into two foundations: individualizing and binding (van Leeuwen \& Park, 2009).

\section{(ii) The Rational-Experiential Inventory}

The REI (Pacini \& Epstein, 1999) is a 40-item measure made up of two subscales: rational and experiential. The rational subscale asks participants to report on preferences for thinking logically and analytically. The experiential subscale asks participants to report on preferences for thinking intuitively and emotionally.

\section{(iii) Political Orientation}

Participants completed a single-item 7-point measure of political orientation $(1=$ extremely liberal to $7=$ extremely conservative). This single-item political orientation mea- sure has been found to have strong predictive validity in prior studies (Graham, Haidt, \& Nosek, 2009).

\section{(iv) Disgust Scale-Revised}

The DS-R (Olatunji, Sawchuk, de Jong, \& Lohr, 2007) is a 25-item measure which taps individual differences in reactions to disgust-eliciting stimuli. Items are measured on a five-point scale from "strongly disagree" to "strongly agree."

\section{Analytical Procedures}

To test our hypotheses, we fit a series of ordinary least squares (OLS) linear regression models separately for each of the subscales of the MFQ (see above) with gender, the DS-R, political orientation, and the REI entered as predictors. Stepwise regression was also conducted to assess the strength and magnitude of each of the predictors in explaining the variance in the outcome.

\section{Results}

Tables 1 and 2 present the findings of our analysis of the relationships between the morality subscales of the MFQ, rational and experiential cognition, political orientation, and disgust. After controlling for political orientation, disgust, and gender in our regression models, the relationships between individualizing morality and rational cognition were significant, but those for experiential and binding morality were not (harm/fairness and rational, $\beta=.231, \beta=.162$ respectively, all $p<.001$; ingroup/authority/purity and experiential, $\beta=.039, \beta=$ $.009, \beta=.048$ respectively, all $p>.500$ ). For the binding morality subscales, rational cognition was significantly and negatively related to rationality $(\beta=-.139, \beta=-.094, \beta=$ -.103 , respectively, all $p<.001$ ). Moreover, once controls were added, the relationship between individualizing foundation and disgust disappeared but remained for all three subscales of binding foundation $(\beta=.028, \beta$ $=-.001$, for harm/fairness, respectively, all $p>.500)$; ingroup, authority, and purity, $\beta=.089, \beta=.071, \beta=.116$, respectively, $p<.001$ ).

Finally, we found that political orientation and rationality were both strongly related to all of the individualizing and binding subscales. Using standard stepwise regression, we further examined the relationships of each of these predictors to these outcomes by examining their overall contribution to variance in the outcome explained. In four out of the five subscales (purity being the exception), rationality, not political orientation, was

Table 1. Pearson Zero-order Correlations among Study Variables

\begin{tabular}{|c|c|c|c|c|c|c|c|c|c|}
\hline & Measure & 1 & 2 & 3 & 4 & 5 & 6 & 7 & 8 \\
\hline 1. & Rational & - & & & & & & & \\
\hline 2. & Experiential & $-.25^{* *}$ & - & & & & & & \\
\hline 3. & Harm & $.50^{* *}$ & $.24^{* *}$ & - & & & & & \\
\hline 4. & Fairness & $.47^{* *}$ & $-.29^{* *}$ & $.78^{* *}$ & 一 & & & & \\
\hline 5. & Ingroup & $-.52^{* *}$ & $.25^{* *}$ & -.07 & -.04 & - & & & \\
\hline 6. & Authority & $-.44^{* *}$ & $.19^{* *}$ & -.07 & -.08 & $.70^{* *}$ & - & & \\
\hline 7. & Purity & $-.47_{* * *}^{* *}$ & $.25_{* *}^{* *}$ & -.02 & -.05 & $.66_{* * *}^{* *}$ & $.64_{* * *}^{* *}$ & - & \\
\hline 8. & Liberal/Conserv. & $-.43^{* *}$ & $.17^{* *}$ & $-.32^{* *}$ & $-.32_{* * *}^{* *}$ & $.41_{* * *}^{* *}$ & $.40^{* *}$ & $.45^{* *}$ & - \\
\hline 9. & Disgust & $-.46^{* *}$ & $.28^{* *}$ & -.05 & $.13^{* *}$ & $.30^{* *}$ & $.32^{* *}$ & $.42^{* *}$ & $.21^{* *}$ \\
\hline
\end{tabular}

${ }^{*} p<.01,{ }^{* *} p<.001$ 
Table 2. OLS Regression of Moral Foundations Questionnaire Subscales and Rational/Experiential Scales

\begin{tabular}{lccccc}
\hline & \multicolumn{2}{c}{ Individualizing } & \multicolumn{3}{c}{ Binding } \\
\cline { 2 - 6 } & Harm & Fairness & Ingroup & Authority & Purity \\
\hline Intercept & 24.284 & 31.128 & 27.279 & 28.122 & 16.261 \\
Rational & $.231^{* * *}(.028)$ & $.162^{* * *}(.025)$ & $-.139^{* * *}(.024)$ & $-.094^{* * *}(.021)$ & $-.103^{* * *}(.025)$ \\
Experiential & $-.073^{*}(.029)$ & $-.092^{* * *}(.026)$ & $.039(.026)$ & $.009(.023)$ & $.048(.026)$ \\
Liberal-Conservative & $-1.03^{* * *}(.266)$ & $-.846^{* * *}(.238)$ & $1.29^{* * *}(.232)$ & $1.08^{* * *}(.203)$ & $1.64^{* * *}(.239)$ \\
Disgust & $.028(.022)$ & $-.001(.020)$ & $.089^{* * *}(.019)$ & $.071^{* * *}(.017)$ & $.116^{* * *}(.020)$ \\
Female & $2.39^{* *}(.741)$ & $1.48^{*}(.663)$ & $-2.66^{* * *}(.646)$ & $-.397(.567)$ & $-1.97^{* *}(.663)$ \\
\hline Adjusted R-squared & .333 & .289 & .401 & .311 & .419 \\
\hline
\end{tabular}

Note. Standard errors in parentheses.

$* p<.05, * * p<.01, * * * p<.001$

the strongest predictor and explained the lion's share of the variance in both the individualizing (where it was positively related: stand. $\beta=.434, \Delta r^{2}=.27$; stand. $\beta=$ $.351, \Delta r^{2}=.24$, respectively) and binding foundations (where it was negatively related: stand. $\beta=-.285, \Delta r^{2}=$ .28 ; stand. $\beta=-.235, \Delta r^{2}=.21$; stand. $\beta=-.201, \Delta r^{2}=.04$, respectively).

\section{Discussion}

Overall, our findings provide marginal support for all three hypotheses. On one hand, our findings support the conclusions of the social intuitionist model by showing that, at the very least, the binding foundations are highly non-rational (i.e., experiential/emotional/System 1). However, to add additional complexity to this model, our findings suggest that a preference for rational thinking (i.e., System 2) in moral judgment is a central component of the individualizing foundations. Political orientation is an important predictor of moral attitudes, but an individual's preference for rational versus non-rational cognition is stronger.

While Haidt claims that moral cognition is intuitive, we found a more complex picture: low rational and high intuitive scores are characteristic of the binding moral foundations, but the opposite is true of the individualizing moral foundations. Rather than an exploration of right and wrong, the binding and individualizing moral foundations would seem to reflect how far from one's kin or ingroup individuals are willing to extend sympathetic consideration. The binding items from the MFQ illustrate parochial morality (relevant primarily to one's own group), whereas the individualizing items illustrate universalizing morality (an extension of consideration beyond one's own group; Lahti, 2009, p. 70).

\section{Conclusion}

We believe the findings of this paper provide provisional empirical support for Lahti's concept of expanding concentric circles of morality. Lahti (2009) based his hypothesis on Darwin's (1871) claim that “...as man gradually advanced in intellectual power... his sympathies became more tender and widely diffused, extending to men of all races" (p. 282). As Lahti (2009) claimed “... these traits (rational cognitive ability and an extension of human sympathies to more inclusive social categories) are unlikely to have arisen by coincidence in the same species over the same period of time" (p. 67). Future study is needed, but we would tentatively suggest that binding and individualizing moral foundations are not different in kind but in degree. That is, both systems are based on a similar concept of morality - to extend help to those in need-but the consideration of sympathy extends at least a little further in individualizing than in binding morality. Achieving this extension, we argue, requires a more objective, rational cognitive faculty. In other words, rationality is not necessarily corollary to showing loyalty to your ingroup (kin) or to exhibiting sensitivity to disgusting behavior; however, seeing the benefit in cooperating outside your kin group likely requires more deliberate rational thought.

\section{Acknowledgements}

We would like to thank the reviewers for their helpful comments.

\section{References}

Darwin, C. (1871). The descent of man, and selection in relation to race. London: John Murray.

Dunbar, R. (2003). The social brain: Mind, language, and society in evolutionary perspective. Annual Review of Anthropology, 32, 163-181. doi:10.1146/annurev. anthro.32.061002.093158

Graham, J., Haidt, J., \& Nosek, B. A. (2009). Liberals and conservatives rely on different sets of moral foundations. Journal of Personality and Social Psychology, 96, 1029-1046. doi:10.1037/a0015141)

Haidt, J., \& Graham, J. (2007). When morality opposes justice: Conservatives have moral intuitions that liberals may not recognize. Social Justice Research, 20, 98-116. doi:10.1007/s11211-007-0034-Z)

Hamilton, W. D. (1964). The genetical evolution of social behaviour. I. Journal of Theoretical Biology 7, 1-16. doi:10.1016/0022-5193(64)90038-4)

Kohlberg, L. (1969). Stage and sequence: The cognitivedevelopmental approach to socialization. In D. Goslin (Ed.), Handbook of socialization: Theory and research (pp. 347-480). Chicago, I Rand McNally.

Lahti, D. C. (2009). The correlated history of social organization, morality, and religion. In E. Voland \& 
W. Schiefenhövel (Eds.), The biological evolution of religious mind and behavior: The frontiers collection (pp. 67-88). Berlin: Springer-Verlag. doi:10.1007/9783-642-00128-4

Lahti, D. C., \& Weinstein, B. S. (2005). The better angels of our nature: Group stability and the evolution of moral tension. Evolution and Human Behavior, 26, 47-63. doi:10.1016/i.evolhumbehav.2004.09.004)

Olatunji, B. O., Sawchuk, C. N., de Jong, P. J., \& Lohr, J. M. (2007). Disgust sensitivity and anxiety disorder symptoms: Psychometric properties of the Disgust Emotion Scale. Journal of Psychopathology and Behavioral Assessment, 29, 115-124. doi:10.1007/s10862-0069027-8)

Pacini, R., \& Epstein, S. (1999). The relation of rational and experiential information processing styles to personality, basic beliefs, and the ratio-bias phenomenon. Journal of Personality and Social Psychology, 76, 972-987. doi:10.1037/0022-3514.76.6.972)

Piaget, J. (1965). The moral judgment of the child. New York: Free Press.

Shweder, R. A., \& Haidt, J. (2000). The cultural psychology of the emotions: Ancient and new. In M. Lewis \& J. Haviland (Eds.), Handbook of emotions (2nd ed., pp. 397-414). New York: Guilford.

Stanovich, K. E., \& West, R. F. (2000). Individual differences in reasoning: Implications for the rationality debate. Behavioral and Brain Sciences, 23, 645-665. doi:10.1017/S0140525X00003435)

Tybur, J. M., Lieberman, D. L., \& Griskevicius, V. G. (2009). Microbes, mating, and morality: Individual differences in three functional domains of disgust. Journal of Personality and Social Psychology, 29, 103-122. doi:10.1037/a0015474

Van Leeuwen, F., \& Park, J. H. (2009). Perceptions of social dangers, moral foundations, and political orientation. Personality and Individual Differences, 47, 169173. doi:10.1016/i.paid.2009.02.017) 